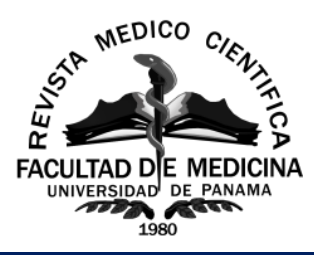

\title{
Procreación natural versus ectogénesis
}

\section{Natural procreation versus ectogenesis}

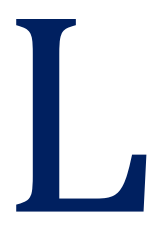

a vida humana se inicia con la fecundación, la cual ocurre por la unión de los gametos femenino y masculino, dando origen al cigoto que cuenta con un genoma individual derivado de ambos progenitores. Posteriormente, el cigoto se implanta en el útero iniciando el embarazo. Según un estudio realizado por Pereira. J y cols (2020), en la actualidad una de cada seis parejas en edad fértil tiene problemas para conseguir un embarazo de forma natural ${ }^{[1]}$; por ello, con la intención de brindar apoyo extracorpóreo para la procreación, se implementaron las Técnicas de Reproducción Humana Asistida (TRHA), que con el nacimiento del primer "bebé probeta" L. Brown (1978) han ido evolucionando para ayudar a superar los problemas de infertilidad. ${ }^{[2]}$

Para lograr sus fines la TRHA recurre a distintos métodos como la "maternidad subrogada o vientre de alquiler" y también a técnicas en desarrollo como la ectogénesis, con su proyecto: "útero artificial o Biobag" (2017). Dicha técnica puede ser de tipo parcial, cuando los sujetos se desarrollan en el útero artificial antes de ser transferidos, o de manera completa, donde su desarrollo es totalmente en la Biobag. ${ }^{[3]}$ Con respecto al útero de alquiler, fue el abogado Noel Keane (1976) quien realizó el primer contrato legal de gestación subrogada y en 1980 se firmó el primer acuerdo de subrogación compensada. Actualmente, esta técnica es un fenómeno comercial global, existiendo diversas agencias encargadas de su desarrollo. ${ }^{[4]}$

Para efectos de comparar los usos, aplicaciones e implicaciones bioéticas entre la maternidad subrogada y la ectogénesis, realizamos una revisión bibliográfica de un total de 39 artículos con fecha de publicación restringida a los últimos 5 años.
En nuestro análisis encontramos que la ectogénesis parcial reduciría las altas tasas de morbimortalidad entre los prematuros, representando una mejor alternativa que las cámaras incubadoras neonatales. Es presumible que esto traería cuestionamientos sobre el aborto por su impacto en la viabilidad del feto. En tanto que para la ectogénesis total se visualizan los dilemas éticos sobre la realización de investigaciones con embriones humanos. ${ }^{[5]}$

Por otra parte, según algunos defensores de la subrogación, las mujeres deben mantener el autocontrol y la libertad total de sus cuerpos, pero es necesario considerar que esta práctica se ejerce en un contexto social que reduce los cuerpos a objetos. La ectogénesis por su parte plantea subcontratar a una máquina, que monitorearía cuidadosamente cada momento de la vida del feto, lo que ayudaría a discernir sus implicaciones éticas, facilitando las intervenciones al tratarlo de forma independiente. ${ }^{[5,6]}$

Cabe mencionar que, si bien la subrogación materna ofrece una fuente de ingresos para las más desfavorecidas, estas no eligen libremente porque viven coaccionadas por la pobreza; además, algunas agencias de subrogación someten a las madres a regímenes severos, llegando a aislarlas para un mayor control, incluso estas son adoctrinadas para ignorar los lazos con el bebé, desnaturalizando su trabajo y degradando la maternidad. ${ }^{[6]}$

Si objetamos que la maternidad es un obstáculo en el camino hacia la emancipación de la mujer podríamos establecer que la ectogénesis las liberaría, mejorando sus derechos y permitiendo con esto que ellas compartan el trabajo de gestación con los hombres, aunque esta acción podría romper la relación entre madre, feto y maternidad. ${ }^{[5,6]}$ 


\begin{tabular}{|c|c|c|}
\hline & Utilidad & Implicancias Bioéticas \\
\hline \multirow{6}{*}{$\begin{array}{l}\text { Útero } \\
\text { Artificial }\end{array}$} & $\begin{array}{l}\text { Reducción de morbimortalidad en prematuros antes de las } \\
24 \text { semanas. }\end{array}$ & $\begin{array}{l}\text { Cuestiones legales y éticas sobre los derechos del aborto al } \\
\text { determinar su viabilidad. }\end{array}$ \\
\hline & Subcontrata el embarazo a una máquina. & Solución a la subrogación materna. \\
\hline & Desarrollo completo del feto fuera del útero materno. & $\begin{array}{l}\text { Dilemas morales sobre las investigaciones con embriones } \\
\text { humanos. }\end{array}$ \\
\hline & Facilitar las intervenciones fetales. & $\begin{array}{l}\text { Responsabilidades morales entre los intereses fetales y los } \\
\text { intereses de la madre. }\end{array}$ \\
\hline & Monitoreo total del feto mediante una máquina. & Rompe el vínculo de entre madre, feto y maternidad. \\
\hline & $\begin{array}{l}\text { Liberar a las mujeres del rol de la maternidad, permitiendo } \\
\text { que compartan el trabajo de gestación con los hombres. }\end{array}$ & Rompe el vínculo entre madre, feto y maternidad. \\
\hline \multirow{5}{*}{$\begin{array}{l}\text { Útero de } \\
\text { Alquiler }\end{array}$} & Mujeres con autocontrol total de sus cuerpos. & Reducción de sus cuerpos a objetos manipulables. \\
\hline & Fuente de ingresos para las mujeres desfavorecidas. & $\begin{array}{l}\text { Mujeres coaccionadas por la pobreza y las faltas de } \\
\text { oportunidades. }\end{array}$ \\
\hline & $\begin{array}{l}\text { Contratos precisos que protegen los derechos de la mujer } \\
\text { subrogada. }\end{array}$ & $\begin{array}{l}\text { Las mujeres no eligen libremente ya que carecen de } \\
\text { suficiente información sobre riesgos para su salud. }\end{array}$ \\
\hline & $\begin{array}{l}\text { Mujeres renuncian a sus derechos y responsabilidades } \\
\text { sobre el bebé. }\end{array}$ & $\begin{array}{l}\text { Las madres desnaturalizan su trabajo y degradan la } \\
\text { maternidad. }\end{array}$ \\
\hline & $\begin{array}{l}\text { Las madres se someten a regímenes severos, aislándolas } \\
\text { de sus familias para aumentar control y vigilancia. }\end{array}$ & Los regímenes comparten paralelismos con la esclavitud. \\
\hline
\end{tabular}

Fuente: Elaborado por el autor.

Al comparar ambas técnicas, como se muestra en la Tabla 1, podemos concluir que, si se llegara a desarrollar la ectogénesis, esta podría convertirse en una alternativa más eficiente que la maternidad subrogada, promoviendo un mayor beneficio por su aplicación.
Sin embargo, no podemos ignorar los grandes dilemas éticos que implica su uso, por lo cual se requiere un mayor análisis antropológico y biomédico para su aplicación. Todo esto con el fin de responder la interrogante de si todo lo técnicamente posible (de llegar a serlo) es lo éticamente correcto.

\section{Patricia Elizabeth Hoces Guerrero (i)*, Cesar Ñique Carbajar (iD \\ *Estudiante de la Facultad de Ciencias de la Salud, Universidad Señor de Sipan. Lambayaque, Perú †Bioetisista y Docente de la Facultad de Ciencias de la Salud, Universidad Señor de Sipan. Lambayeque, Perú}




\section{REFERENCIAS}

[1] Pereira Calvo J, Pereira Rodríguez Y, Quirós Figueroa L. Infertilidad y factores que favorecen su aparición. Rev.méd.sinerg. 2020;5(5):e485.

DOI: https://doi.org/10.31434/rms.v5i5.485

[2] Gamboa Bernal G. LAS TÉCNICAS DE REPRODUCCIÓN ASISTIDA (TRA) A LA LUZ DE LA BIOÉTICA. Escritos. 2016; 24(53): 322-326.

DOI: http://dx.doi.org/10.18566/escr.v24n53.a05

[3] Partridge E, Davey $M$, Hornick $M$ et al. An extra-uterine system to physiologically support the extreme premature lamb. Nat Commun. 2017; 8(1): 2-14.

DOI: https://doi.org/10.1038/ncomms15112
[4] Deonandan R. Thoughts on the ethics of gestational surrogacy: perspectives from religions, Western liberalism, and comparisons with adoption. J Assist Reprod Genet. 2020; 37(2):269-279.

DOI: https://doi.org/10.1007/s10815-019-01647-y

[5] Di Stefano L, Mills C, Watkins A, Wilkinson D. Ectogestation ethics: The implications of artificially extending gestation for viability, newborn resuscitation and abortion. Bioethics. 2019; 34(4): 371-384.

DOI: https://doi.org/10.1111/bioe.12682

[6] Rozée V, Unisa S, de La Rochebrochard E. The social paradoxes of commercial surrogacy in developing countries: India before the new law of 2018. BMC Women's Health. 2020; 234(20)(1):2-13.DOI: https://doi.org/10.1186/s12905-020-01087-2 